\title{
Awareness of atrial fibrogenesis and natriuretic peptide release
}

\author{
W. C. F. W. Meijers ${ }^{1}$ T. Jaarsma ${ }^{2}$ D. J. van Veldhuisen ${ }^{1} \cdot$ T. Hoekstra ${ }^{1}$ R. A. de Boer ${ }^{1}$
}

Published online: 9 February 2017

(c) The Author(s) 2017. This article is available at SpringerLink with Open Access.

We thank dr. Lucas for her comments regarding our article in which we described patients with heart failure with preserved ejection fraction (HFpEF) and low levels of natriuretic peptides. In this article [1], we described that HFpEF patients with relatively low B-type natriuretic peptide (BNP) levels have strikingly similar clinical characteristics as HFpEF patients with elevated BNP levels, except for BMI, which was significantly higher in the first group. Clinicians might expect that low BNP levels are associated with low risk of adverse events, but, as recently observed in another study [2], NP-proBNP and BNP are not the ideal markers to identify low-risk patients.

The hypothesis, shared by dr. Lucas, that the stiff left atrial syndrome might explain the low BNP levels observed in HFpEF patients is interesting. The stiff left atrium has mostly been described after ablation therapy for atrial fibrillation (AF) [3, 4]. However, we agree that also in heart failure, atrial tissue may remodel and become stiff. It has indeed been suggested that heart failure patients with a longer duration of $\mathrm{AF}$ exhibit advanced remodelling of the atrial tissue, in which atrial cardiomyocytes are replaced by fibrotic tissue, a hallmark of remodelling [5]. The remaining atrial tissue no longer produces natriuretic peptides, with pseudo-low natriuretic peptide levels as a result [6].

Reply to the letter 'Stiff left atrial syndrome as another cause for heart failure with preserved ejection fraction and normal BNP levels'.

R. A. de Boer

r.a.de.boer@umcg.nl

1 Department of Cardiology, University Medical Centre, University of Groningen, Groningen, The Netherlands

2 Faculty of Health Sciences, Linköping University, Linköping, Sweden
However, in our study we observed a comparable prevalence of AF in both groups (BNP $<100 \mathrm{pg} / \mathrm{mL}$ vs. BNP $>100 \mathrm{pg} / \mathrm{mL}, 50 \% \mathrm{AF}$ in both groups), suggesting the severity of atrial remodelling is equal. Further, advanced atrial remodelling would most likely be accompanied by higher levels of inflammatory and fibrotic biomarkers. But the levels of galectin-3, a fibrotic protein associated with worse outcome [7], and interleukin-6, an inflammatory biomarker, were comparable between both groups.

Preferably, we would have assessed cardiac and atrial dimensions by echocardiography, but, unfortunately, we do not have these data in the COACH database and acknowledge this as a limitation of our study.

So, based on the data presented, we cannot demonstrate evidence that the low BNP levels in our study were due to progressed atrial remodelling. But we agree that studying the left atrium is of importance in HF patients with paroxysmal or persistent $\mathrm{AF}$ and in patients who have pseudo-low BNP levels. Indeed, stiffening of the left atrium may clinically be under-recognized and more awareness is needed.

Open Access This article is distributed under the terms of the Creative Commons Attribution 4.0 International License (http:// creativecommons.org/licenses/by/4.0/), which permits unrestricted use, distribution, and reproduction in any medium, provided you give appropriate credit to the original author(s) and the source, provide a link to the Creative Commons license, and indicate if changes were made.

\section{References}

1. Meijers WC, Hoekstra T, Jaarsma T, van Veldhuisen DJ, de Boer RA. Patients with heart failure with preserved ejection fraction and low levels of natriuretic peptides. Neth Heart J. 2016;24(4):287-95.

2. Meijers WC, de Boer RA, van Veldhuisen DJ, Jaarsma T, Hillege HL, Maisel AS, et al. Biomarkers and low risk in heart 
failure. Data from COACH and TRIUMPH. Eur J Heart Fail. 2015;17(12):1271-82.

3. Clare GC, Margulescu AD, Leong FT. Stiff left atrial syndrome following left atrial appendage resection and multiple ablations for atrial fibrillation. Heart 2013;99(7):508-2012-303171. Epub 2012 Dec 12.

4. Gibson DN, Di Biase L, Mohanty P, Patel JD, Bai R, Sanchez J, et al. Stiff left atrial syndrome after catheter ablation for atrial fibrillation: clinical characterization, prevalence, and predictors. Heart Rhythm. 2011;8(9):1364-71.
5. Piek A, de Boer RA, Sillje HH. The fibrosis-cell death axis in heart failure. Heart Fail Rev. 2016;21(2):199-211.

6. Van Den Berg MP, Crijns HJ, Van Veldhuisen DJ, Van Gelder IC, De Kam PJ, Lie KI. Atrial natriuretic peptide in patients with heart failure and chronic atrial fibrillation: role of duration of atrial fibrillation. Am Heart J. 1998;135(2 Pt 1:242-4.

7. Meijers WC, Januzzi JL, deFilippi C, Adourian AS, Shah SJ, van Veldhuisen DJ, et al. Elevated plasma galectin-3 is associated with near-term rehospitalization in heart failure: a pooled analysis of 3 clinical trials. Am Heart J. 2014;167(6):853-860.e4. 